\title{
Polaridades Conceituais e Tensões Teóricas no Campo da Psicologia: O Falso Paradoxo Indivíduo/Coletividade
}

Conceptual Polarities And Theoretical Tensions In The Field Of
Psychology: The Individual / Collective False Paradox

Polaridades Conceptuales Y Tensiones Teóricas En El Campo De La Psicología: La Falsa Paradoja Individuo / Colectividad
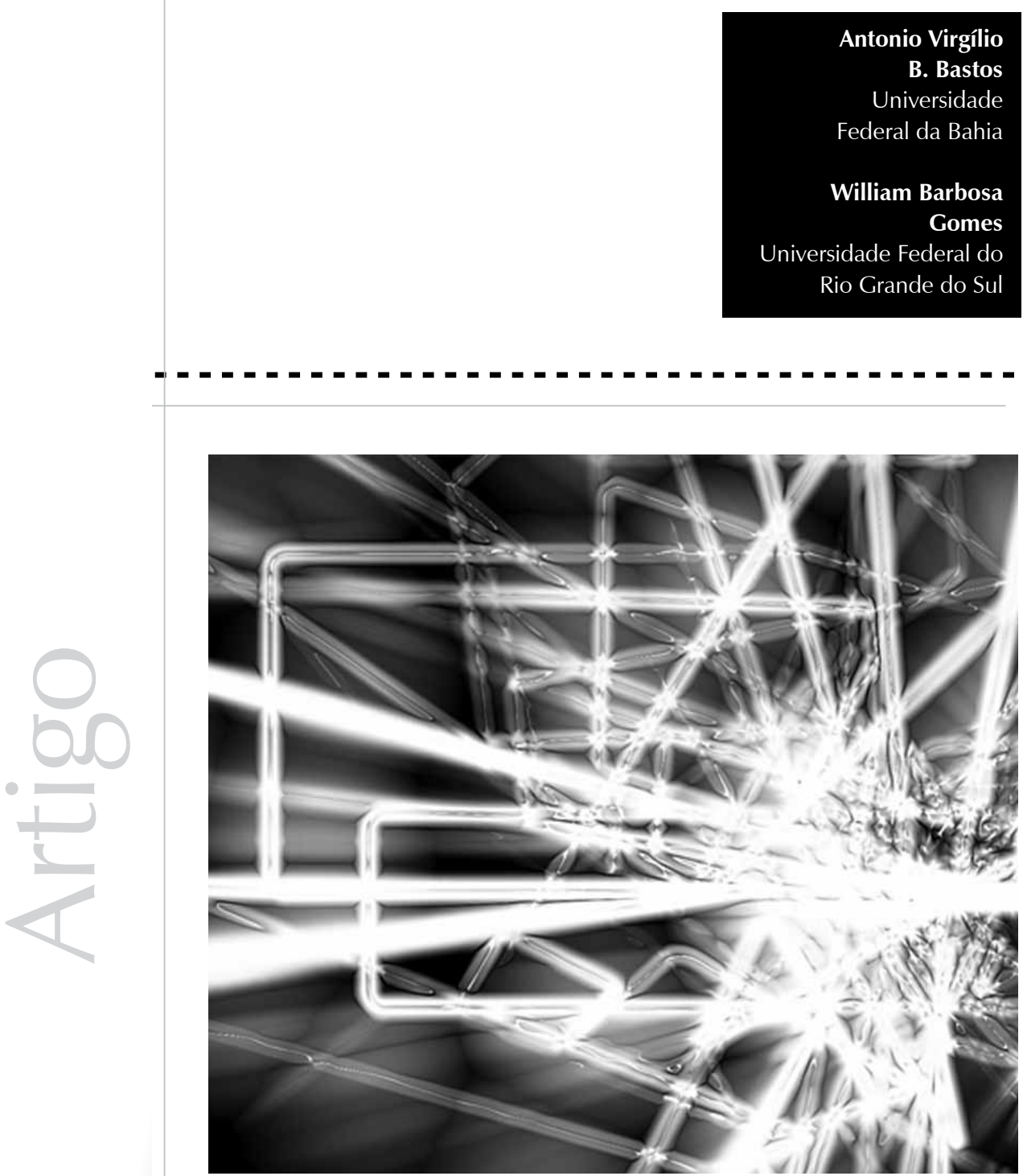
Resumo: O presente artigo analisa as polaridades que dificultam o diálogo entre os psicólogos e o estudo da Psicologia e argumenta que as tensões decorrentes estão mais associadas às ações utilizadas para lidar com o problema do que às questões teóricas propriamente. Essas tensões procedem de relações complexas que não podem ser reduzidas aos respectivos polos e que devem ser examinadas em diferentes níveis de análise. O argumento é ilustrado com relação ao individual e ao coletivo no contexto da Psicologia organizacional. Conclui-se que o encaminhamento dos dilemas e das tensões no campo com repercussões importantes na formação e na prática profissional requer superação dos nossos aprisionamentos teórico-metodológicos, convivência com a pluralidade teórico-metodológica e integração crítica e construtiva das muitas perspectivas que elucidam a natureza e a manifestação de um fenômeno.

Palavras-chave: Formação do psicologo. Currículo. Psicologia social. Epistemologia.

Abstract: This article examines the polarities that hinder dialogue among psychologists and the study of the discipline. The argument points out that the tensions are associated more strongly to the actions used to deal with the problem than to theoretical issues properly. These tensions stem from a complex relationship which cannot be reduced to their respective poles and must be examined on different levels of analysis. The argument is illustrated with the relationship individual-collectivity from organizational psychology context. The study concludes that the routing of the dilemmas and tensions in the psychological field and training requires overcoming our theoretical and methodological lockups, coping with the theoretical and methodological plurality, and pursuing a critical and constructive integration from the many perspectives that elucidate the nature and manifestation of the psychological phenomena.

Keywords: Psychologist education. Curriculum. Social psychology. Epistemology.

Resumen: El presente artículo analiza las polaridades que dificultan el diálogo entre los psicólogos y el estudio de la Psicología y argumenta que las tensiones derivadas están más asociadas a las acciones utilizadas para tratar con el problema que a las cuestiones teóricas propiamente. Esas tensiones proceden de relaciones complejas que no pueden ser reducidas a los respectivos polos y que deben ser examinadas en diferentes niveles de análisis. El argumento es ilustrado con relación al individual y al colectivo en el contexto de la Psicología organizacional. Se concluye que el encaminamiento de los dilemas y de las tensiones en el campo con repercusiones importantes en la formación y en la práctica profesional requiere superación de nuestros aprisionamientos teórico-metodológicos, convivencia con la pluralidad teórico-metodológica e integración crítica y constructiva de las muchas perspectivas que elucidan la naturaleza y la manifestación de un fenómeno.

Palabras clave: Formación del psicologo. Currículo. Psicología social. Epistemología.

O pensamento psicológico move-se entre polaridades, tensões e paradoxos decorrentes das características ontológicas desse campo de conhecimento (Barrett, 2009). Em termos ontológicos (Wiley, 1994), a Psicologia se caracteriza como área de interseção entre as ciências físicas e biológicas, de um lado, e entre as ciências sociais, interativas e culturais do outro. Ontologia é aqui definida como um ente ou objeto e seu logos, isto é, o espaço no qual o ente se revela como tal para a elucidação do sujeito cognoscente. Com efeito, a Psicologia constitui uma grande região ontológica, e permite circunscrições variadas, apropriações diversas e diferentes perspectivas. Desse modo, as polaridades aparecem naturalmente nas tensões teóricas dentro do campo e constituem eixos nos quais estudantes, professores, pesquisadores e profissionais terminam se posicionando, muitas vezes de forma rígida e sem o respaldo de discussões aprofundadas (Searle, 1995).

Há polaridades muito conhecidas e referenciadas. Ao se discutir a relação entre indivíduo e ambiente, aparece a tensão construtor/ativo versus construído/passivo (Kimble, 1984; Nunez, Poole, \& Menon, 2003). Ao examinar a constituição do sujeito ao longo do ciclo de vida, deparamo-nos com a tensão do inato versus adquirido, ou de natureza versus cultura (Baillargeon, 2008; Keating, 2007; Lewkowicz, 2011). Ao considerarmos a singularidade do indivíduo, vemo-nos diante do dilema estrutura versus processo, ou estrutura versus ação (Archer, 2003). Ao analisarmos a questão de ajustamento, do bem-estar e 
da saúde, enfrentamos a tensão do conceito e dos limites entre normal versus patológico (Ganellen, 2007). Ao tratarmos dos processos de investigação, temos que enfrentar o dilema qualitativo versus quantitativo ou, mais abrangentemente, ciências naturais versus ciências sociais, decorrendo daí outras polaridades como positivismo versus não positivismo, dialética versus hermenêutica, e assim por diante (Denzin \& Lincoln, 2000). Ao pensarmos sobre o conjunto diversificado de práticas profissionais, nós nos deparamos com a categorização de práticas individualizantes versus práticas coletivas ou, ainda, de práticas remediativas versus práticas preventivas (Ayres, 2001). Concluída essa breve lista, apresenta-se a polaridade que será analisada nesta exposição: a tensão indivíduo-coletividade que, na sua acepção mais ampla, aparece no dilema indivíduocoletividade. Tal dilema, na realidade, se ancora em outro maior: na relação entre parte e todo, singular e plural, indivíduo e sociedade, e nos diversos níveis e planos em que as pessoas se agrupam. Assim, trata-se de uma tensão que atravessa a discussão das relações das pessoas com seus vários grupos de inserção: família, grupos de amigos, grupos de trabalho, organizações, etc. Pode-se, também, expressar esse dilema em termos polares, tais como: subjetividade versus objetividade, subjetividade versus estrutura social, eu versus outro, ou identidade individual versus identidade coletiva (Strauss, 1999).

À primeira vista, chega a ser assustadora a quantidade de dilemas que temos de equacionar e que exigem posicionamentos de professores (que já os possuem, muitas vezes com elevado grau de segurança) e de Psicologia (muitas vezes perdidos nesse emaranhado de questões e de disputas que marcam o nosso domínio). A quantidade desses dilemas e paradoxos não é, certamente, um problema a ser superado, se isso fosse possível. Trata-se de decorrência, como já afirmado anteriormente, da singularidade do nosso campo científico e profissional no conjunto de campos de conhecimento e, certamente, dos nossos objetos de estudos, que sempre estão a requerer longos prolegômenos e justificações. $\mathrm{Na}$ verdade, as dificuldades estão mais associadas ao modo como educadores lidam com tais dilemas e paradoxos do que com as posições efetivamente assumidas por teóricos e cientistas.

O presente estudo analisa uma dessas polaridades listadas, o paradoxo indivíduo versus coletividade, como exemplo das implicações dessas dicotomias na compreensão da teoria psicológica, no diálogo entre psicólogos e entre estes e outros profissionais e na própria formação profissional. O argumento principal é que as tensões estão associadas mais fortemente às ações utilizadas para lidar com o problema do que às questões teóricas propriamente. Nas conclusões, discute-se como as polaridades e as tensões do campo psicológico fragmentam a teoria e confundem a formação.

\section{O paradoxo indivíduo - coletividade}

Em geral, duas grandes alternativas se colocam com mais frequência diante das polaridades: 1) reducionismo e 2) conciliação. A alternativa reducionista indica a opção por um dos lados, relegando o polo oposto a um status ontológico frágil, mera expressão ou resultado de processos que acontecem no polo escolhido. Tal opção desencadeia processos de construção de identidades coletivas, valorizando tudo o que se aproxima do polo que se defende e se acredita. Fortalece-se, assim, a identidade de pertencimento ao grupo e desconsideram-se as características externas.

A alternativa de conciliação ou de coexistência de opostos reconhece que ambos os lados da polaridade são legítimos e que eles 
trazem perspectivas importantes para serem examinadas. Eles avançam ainda mais ao indicar que, em certas ocasiões ou contextos, tais fenômenos podem até mesmo ser conciliados. Em lugar de um jogo tudo versus nada, eles sugerem um tudo versus tudo (ou quase tudo). Todavia, a perspectiva de se olhar os diferentes polos naquilo que eles podem ajudar a compreender uma dada condição termina por impedir a descrição clara do fenômeno, não explicando como tais polos se articulam efetivamente.

De forma intuitiva, sabemos que vivemos imersos em vários agrupamentos sociais, de diferentes amplitudes e complexidades. Ao longo de todo o ciclo vital, transitamos por diferentes grupos, dos mais básicos (família nuclear, família extensiva) aos mais distantes e abstratos (organização e sociedade, por exemplo). Na realidade, podemos pensar que o mundo social se estrutura como um complexo de coletividades incrustadas em coletividades cada vez maiores, em redes nas quais transitamos em distintos momentos, espaços e circunstâncias. Tal fato torna central a questão sobre as determinações dos nossos comportamentos, atitudes, valores, forma de ser, de sentir e de perceber o mundo. São tais determinações decorrentes dos âmbitos coletivos e sociais onde estamos inseridos? Do outro lado da polaridade, a pergunta seria: até que ponto as características, o funcionamento, a estrutura, as normas e os valores dessas coletividades maiores nas quais nos inserimos são produtos daquilo que somos, pensamos e fazemos?

Em síntese, a conexão indivíduo-sociedade, como rapidamente apresentada acima, coloca-se como central para a Psicologia por estar na base que delimita o seu espaço no conjunto das ciências sociais ou humanas. Logo, torna-se central para a compreensão teórica e a formação na área, pois lida com eixo fundamental para a compreensão do ser humano, da sua diversidade e das formas como tal diversidade se articula em pensamentos e ações coletivas. Tal centralidade, possivelmente, é que torna essa questão alvo de um acalorado ou apaixonado debate que talvez pudéssemos descrever como uma luta, em que grupos opostos buscam a supremacia da sua posição. Tal debate tem fortes raízes na história da constituição das ciências sociais e da Sociologia, e na necessidade de os primeiros sociólogos diferenciarem a pesquisa sociológica da pesquisa psicológica. Para os pioneiros da Sociologia, a sociedade não era mera soma de indivíduos (Durkheim (1895/1972) e nem uma coisa em si separada dos indivíduos (Weber, 1922/1994). Temos, aí, dois paradigmas seminais neste debate.

\section{Da sociedade ao indivíduo versus do indivíduo à sociedade}

Passemos, a seguir, à análise do que se encontra na base de tais disputas, retomando as estratégias apresentadas acima. As posições extremas se apoiam em duas formas de reducionismo: 1) redução da sociedade ao indivíduo $-\mathrm{S}=\mathrm{f}(\mathrm{I})$ e 2) redução do indivíduo à sociedade $-\mathrm{I}=\mathrm{f}(\mathrm{S})$.

Na redução da sociedade ao indivíduo $-\mathrm{S}=\mathrm{f}(\mathrm{I})$, a sociedade é vista como um somatório das ações individuais, sendo estas suficientes para explicar a sua complexidade e diversidade. Não há uma realidade social fora da ação individual. Logo, todo fenômeno social, inclusive o funcionamento das instituições sociais, deve ser visto como resultante de decisões, atitudes, pensamentos de seres humanos. Toda explicação a partir do coletivo, como em Estado e nação, não é satisfatória. Tal redução implica uma perspectiva que podemos rotular de individualística e voluntarista, como exemplificou a sociologia compreensiva de Max Weber (1864-1920). Na redução do indivíduo à sociedade $\mathrm{I}=\mathrm{f}(\mathrm{S})$, o indivíduo é visto como produto de 


\section{...a sociedade é reificada, tomada como coisa que controla coercitivamente os indivíduos, moldando-os por meio dos processos de socialização, como exemplificou o funcionalismo sociológico de Emile Durkheim} (1858-1917). ${ }^{1}$

1 Tratando-se de um texto voltado para os problemas teóricos e metodológicos em Psicologia, convém lembrar que Durkheim foi à Alemanha, entre os anos 1885-1886, atraído pelas ideias de W. Wundt (1832-1920), principalmente para estudo do método científico. Durkheim é reconhecido como $\mathrm{o}$ introdutor das pesquisas empíricas em Sociologia

(Harré \& Lamb, 1991). forças e de estruturas sociais. O todo limita, determina, produz, causa manifestações nos indivíduos que passam a ser instâncias de tais forças sociais. Os indivíduos são atores sociais que possuem a habilidade de realizar as funções sociais requeridas pela sociedade. Assim, a sociedade é reificada, tomada como coisa que controla coercitivamente os indivíduos, moldando-os por meio dos processos de socialização, como exemplificou o funcionalismo sociológico de Emile Durkheim (1858-1917). ${ }^{1}$

Ambas as estratégias reducionistas, como vemos, trabalham com uma perspectiva unidirecional da influência de um polo sobre o outro. Há, no entanto, várias tentativas de conciliação dos dois modelos, assumindo que eles se influenciam mutuamente: a estrutura social é produzida pelo homem e o produz. A síntese encontrada reconhece que a estrutura social é uma objetivação da atividade humana, mas que afeta o indivíduo como um fator externo, que o limita e o restringe. No entanto, introduz problemas adicionais para a compreensão de como sociedade e indivíduos se relacionam. A circularidade embutida nessa combinação das duas estratégias reducionistas cria, por exemplo, o problema de como explicar ou compreender os processos de mudança, quer das sociedades em suas múltiplas coletividades, quer dos indivíduos.

Critica-se, portanto, essa estratégia que afirma a coexistência ou a conciliação, articulando os dois reducionismos simultaneamente, na expectativa de que, assim o fazendo, o problema da relação indivíduo-coletividade fica solucionado. Tal solução, no nosso entendimento, gera um paradoxo por desconsiderar os problemas conceituais e a diferença na condição ontológica existente entre os conceitos de indivíduo e de sociedade que estão na base dessa falsa antinomia; em outras palavras, traz um falso dilema que nasce da pouca atenção que dedicamos aos conceitos e às formas que utilizamos no campo científico. O problema está no discernimento da condição ontológica de indivíduo e sociedade. Seriam elas condições comuns ou diferenciadas? $\mathrm{Na}$ realidade, o indivíduo é mais do que aquilo que a sociedade determina, e a sociedade é mais do que aquilo que o indivíduo cria. $\mathrm{O}$ não esclarecimento da extensão desses dois conceitos limita a compreensão de como eles se articulam efetivamente. A seguir, a tensão indivíduo-sociedade será analisada em um contexto específico, a relação indivíduoorganização.

\section{O caso da relação indivíduo- organização}

Uma forma interessante de analisar a tensão que se concretiza na polaridade indivíduo-coletividade é tomar como foco um contexto correspondente e bem delimitado, como, por exemplo, o contexto das organizações ou coletivos sociais voltados para produzir bens e serviços demandados pela sociedade. O campo dos estudos organizacionais tem como uma de suas questões centrais as relações entre indivíduo (pessoas/trabalhadores) e organização. A mesma polaridade a que nos referimos anteriormente se encontra presente nesse domínio, e, a exemplo das posições que antagonizam ou conciliam indivíduo e sociedade, também temos a separação entre o que denominamos comportamento micro e macro-organizacional.

Tratativas para definir o que é organização levam a duas fontes de tensão, claramente associadas: 10: a primazia assumida pela noção de processo versus entidade com implicações para as dimensões verbal e substantiva que estão presentes nos usos cotidianos da palavra organização. Essa polaridade tem como subjacente um posicionamento sobre a natureza ontológica do próprio fenômeno organizacional; $2^{2}$ : 
na verdade uma decorrência, a prioridade que cada teórico atribui aos indivíduos sujeitos ou agentes - e à organização como algo emergente de uma coletividade de pessoas, na determinação dos fenômenos organizacionais, ou seja, aqui se faz presente um dilema enraizado nas clássicas antinomias individual-coletivo, indivíduo-sociedade.

Essas duas tensões se entrecruzam e potencializam perspectivas diferenciadas de compreensão do que sejam as organizações. De início, é importante assinalar que, nas duas dimensões acima, não vamos encontrar soluções tudo-nada, isto é, não temos acesso a tentativas conceituais que desconsiderem as ações pessoais e o seu papel constitutivo do fenômeno coletivo; não vamos encontrar, pelo menos entre os teóricos organizacionais de maior porte, a negação de que uma instância coletiva se diferencia de uma instância individual. As diferenças são, portanto, de ênfase ou de formas de conceber, ontologicamente, a natureza das relações entre atos humanos e seus resultados ou atos individuais e atos envolvidos nas interações entre pessoas.

Ao longo do último século, as soluções teóricas para esses dois dilemas configuraram duas grandes matrizes interpretativas sobre a organização.

A primeira matriz, iniciada pelo movimento das relações humanas e que passa pela abordagem comportamental, concentra-se nos processos envolvidos no organizar-se, opondo-se à tentativa de reificar o conceito de organização, de considerá-lo como algo além de um sistema de indivíduos em interação (Barnard, 1938/1979; Simon, 1945/1979). A segunda matriz, com origem nos estudos sobre burocracia e presente nas abordagens estruturalistas e mesmo sistêmicas, considera a organização como uma entidade, com uma existência própria independente das pessoas e das suas atividades (Etzioni, 1964/1989; Hall, 1984).
A primeira matriz trabalha sob um pressuposto que enfatiza mais o papel do indivíduo ao construir a organização do que o papel determinante da organização sobre os processos individuais. Por essa perspectiva, a compreensão da estrutura e da coordenação da organização está na centralidade de processos decisórios, no comportamento gerencial, na liderança, no comportamento administrativo e nos processos de influência e de coordenação. Historicamente, essa matriz se consolidou como micro-orientada, e representa a vertente dos estudos organizacionais mais fortemente fundamentada na Psicologia.

As linhas mestras dessa primeira matriz ficam explícitas nos seguintes enunciados de dois importantes teóricos que a representam:

São sempre as ações de pessoas, por
palavras, olhares, gestos, movimentos,
nunca objetos físicos, embora coisas
possam ser usadas convenientemente
como evidência da ação, como no caso
da escrita ... coisas físicas são sempre uma
parte do ambiente, uma parte do sistema
cooperativo, mas nunca uma parte da
organização (Barnard, 1938/1979, p.96)
O termo organização refere-se... ao
complexo sistema de comunicações e
interrelações existentes num grupamento
humano. Esse sistema proporciona a cada
membro do grupo parte substancial das
informações, pressupostos, objetivos e
atitudes que entram nas suas decisões,
propiciando-lhes, igualmente, um conjunto
de expectações estáveis e abrangentes
quanto ao que os outros membros do grupo
estão fazendo e de que maneira reagirão ao
que ele diz e faz (Simon, 1945/1979, p. xiv)

A segunda matriz outorga à organização o poder de agência. A organização se comporta, interage com outras organizações, adapta-se aos seus ambientes e é capaz de aprender, entre tantas outras disposições. Essa entidade passa, também, a ser adjetivada: elas, as organizações, podem, por exemplo, ser burocráticas, modernas, complexas, dinâmicas ou competitivas a partir de elementos que as caracterizam. 
Essa é a perspectiva que, historicamente, se consolidou como macro-orientada. É a vertente dos estudos organizacionais mais fortemente fundamentada na Sociologia, na ciência política e na Economia. O pressuposto comum subjacente a essa segunda matriz pode ser percebido nas palavras de outros dois importantes teóricos organizacionais:

Podemos reservar, sem riscos, a palavra organizações para unidades planejadas, intencionalmente estruturadas com o propósito de atingir objetivos específicos (Etzioni, 1964/1989, p. 4)

Deveria ficar claro, (...) entretanto, que as organizações têm características particulares, além da especificidade de objetivos e da continuidade. Elas incluem fronteiras relativamente fixas, uma ordem normativa, posições de autoridade, um sistema de comunicações e um sistema de incentivos que permite aos diversos tipos de participantes trabalhar juntos na consecução dos objetivos comuns (Hall, 1984, p. 22)

Essa separação entre domínios macro ou micro orientados se expressa em uma forte polêmica sobre o poder de agência ou a fonte prioritária de determinação - se está no indivíduo ou na organização, como exemplificada nas argumentações de Hall e de Staw e Sutton (1993). Para Hall, o olhar macro mostra que parte do comportamento das pessoas se deve a fatores organizacionais, e, portanto, as organizações têm o poder de moldar o comportamento e as ações individuais. A posição sustenta-se sob os argumentos de que a organização 1) age por políticas próprias claramente definidas, 2) subsiste no tempo para além das pessoas que a integra, e 3) possui uma estrutura social, um sistema de regras, de normas, de valores e de expectativas que pré-existem ao indivíduo. Em contraste, para Staw e Sutton, o olhar micro destaca indivíduos autônomos que assumem a posição de organização, e que as ações ditas organizacionais seriam, de fato, ações individuais, sob a aparência de uma entidade impessoal. Então, a posição contrastante sustenta-se sob os argumentos de que indivíduos com poder exercem influência e controle para: 1) modelar decisões e estratégias, 2) definir estruturas mais estáveis, 3) modelar percepções de parceiros, 4) modelar características do próprio grupo de pessoas.

Ancorados nessa forte separação indivíduoorganização, os dois campos científicos encontraram, ao longo do tempo, uma forma de convivência que, apesar das tensões permanentes, gerou espaços próprios e que os manteve com reduzida interação ou escassas tentativas de romper os limites que os demarcavam. A concepção de organização como uma entidade torna-se o pensamento hegemônico, já que os indivíduos e os seus processos são vistos como elementos que ocorrem na organização. Assim, temos, por um lado, organizações como entidades a serem compreendidas nas suas relações contextuais, históricas e simbólicas que estruturam a sociedade maior; por outro lado, temos indivíduos dentro das organizações, com seus processos individuais, motivos, necessidades, expectativas, crenças e mecanismos para enfrentar e para lidar com as exigências estabelecidas pela própria organização.

Está assim configurada a estratégia de coexistência e conciliação que pouco avança na compreensão da origem desse paradoxo ou dessa tensão, a exemplo do que acontece quando tratamos da relação mais geral entre indivíduo e sociedade. No caso da relação indivíduo-organização, temos uma condição diferenciada pelo fato de, ao ingressar em uma organização, o indivíduo já possuir uma história e características próprias. Desse modo, seria difícil levar-se ao extremo a possibilidade de uma formatação completa do indivíduo pela organização. Isso, no entanto, não ocorre quando tomamos a sociedade como um todo. 


\section{Como lidar com o paradoxo tensão/polaridade?}

Sociólogos, como Giddens (2003), Bourdieu (1989) e Elias (1994/1990), e psicólogos como Juckes e Barresi (1993) nos oferecem conceitos e modelos teóricos acerca de como se diferenciam e se articulam indivíduo e sociedade. Poderíamos ainda recorrer, como sugeriu Almeida Filho (1997), ao estudo de relações complexas ou ainda a modelos de compreensão e de intervenção indicados por pesquisas empíricas, por exemplo, para o estudo de identidade nacional em situações conflituosas, como palestinos e judeus (David \& Bar-Tal, 2009), ou para o estudo da interatividade e da mudança na relação entre individual e coletivo com estudantes em projetos colaborativos (Hellström, 2007). Tais posições e pesquisas, por suas características heurísticas, estão hoje a merecer atenção mais detida de sociólogos e psicólogos sociais, como veremos a seguir.

Giddens (2003), ao propor o conceito de estruturação, ressalta a dualidade da estrutura, cujas propriedades são tanto o meio quanto o resultado das práticas que constituem os sistemas sociais, ou seja, a estrutura é tanto habilitadora como coercitiva. Para ele, as estruturas não são independentes das atividades que elas regulam e nem dos atores sociais que as constituem. Por conseguinte, os indivíduos, quando atuam em posições sociais, não são inteiramente conhecedores das condições antecedentes e consequentes, e é essa visão parcial de engajamento que mantém a estrutura social. Em síntese, a ação é necessária para a manutenção, mas insuficiente para a criação do aspecto social.

Bourdieu (1989) encaminha a tensão indivíduo-sociedade com dois conceitos: habitus e campo. O habitus é um conjunto de disposições duráveis, resultado da internalização das estruturas sociais. Ele supõe um processo de adaptação de nossas percepções, pensamentos e ações a situações objetivas em que se produzem. Tais disposições estruturam nossas práticas e representações, que tendem a perdurar e a afetar os diferentes campos da nossa atividade. O campo se refere à situação dinâmica em que opera um determinado habitus, sendo, portanto, contextos específicos. Assim, as ações das pessoas, em suas práticas particulares, são resultados da relação entre o habitus e o campo. A sociedade é vista como uma pluralidade de campos nos quais se manifestam as diferenças e os antagonismos sociais.

Elias(1994) substitui a dualidade sujeito-objeto e indivíduo-sociedade pela compreensão de um indivíduo livre e autônomo na relação com o âmbito social, com ênfase na interdependência e nas mudanças assimétricas de poder ao longo do tempo; são as configurações sociais decorrentes das relações e das articulações entre indivíduos e entre indivíduos e sociedades. O autor critica a redução processual, ou seja, a tendência de se reduzir conceitualmente processos a estados. Na Sociologia, a redução processual pode ser vista em distinções conceituais entre o ator e sua atividade, entre estruturas e processos, objetos e relações. Conceitos tais como normas, valores, papéis e classe social parecem existir independentemente dos indivíduos, o que, para Elias, é inapropriado. Para ele, são necessários conceitos mais afins com o estudo de figurações e que tenham como princípio as relações entre pessoas.

Do mesmo modo, psicólogos como Juckes e Barresi (1993), consideram a dimensão objetiva e subjetiva, tanto nos indivíduos quanto na sociedade, como condição para se entender a complexa conexão entre os dois, e como base para o entendimento das mudanças sociais. Para os autores, indivíduo e sociedade são reais e distintos, o que impede que um seja reduzido ao outro. 
No centro do conceito de indivíduo, está a noção de agência, que é a capacidade de engajamento em ação intencional e de subjetividade. A sociedade, por seu lado, apoia-se em uma rede de relações sociais que, por sua vez, constrói uma ordem social. Para os autores, o indivíduo não se reduz às forças da sociedade, pois esta requer um indivíduo que, como ator social, tenha poder de agência, isto é, de deliberação, mesmo que o objetivo venha ser a transformação social. Assim, a sociedade não cria indivíduos, e sim, papéis sociais, e atua na constituição, nem sempre bem sucedida, de atores sociais competentes. Podemos afirmar, então, que a sociedade não determina o indivíduo, mas é a função social que o induz a se tornar um ator social competente.

A polaridade indivíduo-coletividade é, sem dúvida, um fenômeno complexo, e, nesse sentido, pode ser entendida com os níveis de complexidade apresentados por Almeida Filho: a) um objeto que "faz parte de um sistema de totalidades parciais e pode ser compreendido ele mesmo como um sistema, também incorporando totalidades parciais de nível hierárquico inferior", b) um objeto "que não pode ser explicado por modelos lineares de determinação", (c) um objeto que pode, metodologicamente, ser "apreendido em múltiplos níveis de existência, dado que opera em distintos níveis da realidade", e (d) um objeto que é "multifacetado, alvo de diversas miradas, fonte de múltiplos discursos, extravasando os recortes disciplinares da ciência", ou, como o mesmo autor sintetiza a seguir: "um objeto complexo é sintético, não linear, múltiplo, plural e emergente" (1997, p.11).

A noção de complexidade introduz, neste ponto, algo adicional: a necessidade de se buscar o emaranhado de relações, interações e, sobretudo, retroações, como nos fala Morin (1996). O rompimento de um pensamento linear (que tome, por exemplo, características da sociedade/organização como causadoras de reações individuais ou vice-versa) leva o autor a falar sobre a essencialidade do pensamento em espiral, o que significa incorporar o efeito retroativo que ocorre a partir da emergência de resultados ou de produtos gerados pela ação humana. Contudo, ao que consta, essa posição pouco tem avançado quanto a ações concretas.

Por outro lado, recomenda-se cautela ao lidar com relações lineares e facilmente identificáveis entre esses dois complexos fenômenos, em quaisquer das direções em que tais relações sejam estabelecidas. Primeiro, porque estaríamos incorrendo em um erro categórico, ao reificarmos o conceito de sociedade/organização; segundo, porque estaríamos deixando de capturar a natureza eminentemente processual, dinâmica e fluida dessa rede de relações, que articula pessoas, suas ações mediadas por artefatos físicos e simbólicos e os produtos dessas ações, uma rede em que as ações e cognições, individuais e coletivas, em espiral e recursivamente, vão construindo (criando ordem) e dissolvendo (criando desordem) relações, entendimentos recíprocos, explicações e significados compartilhados. Talvez o grande desafio à compreensão de estruturações complexas como as relações entre indivíduos e sociedade/ organizações esteja no desenvolvimento de estratégias metodológicas para explorar e intervir nos processos que articulam pessoas, grupos e organizações.

Uma aplicação dessa visão conceitual pode ser ilustrada por dois estudos recentes. David e Bar-Tal (2009) ofereceram uma análise da complexa estruturação da identidade coletiva em contexto de conflito internacional. No primeiro nível, recorreuse à microanálise para examinar como indivíduos reconhecem e categorizam o pertencimento a um determinado grupo, considerando as implicações cognitivas, emocionais e comportamentais. No segundo 
nível, recorreu-se à macroanálise para examinar a consciência de identidade coletiva compartilhada entre os membros do grupo. O modelo permite o levantamento e a comparação dos fatores peculiares e genéricos entre indivíduos e grupos, podendo contribuir para ações interventivas nos dois níveis. O modelo foi utilizado para estudar as relações entre palestinos e judeus no Oriente Médio. Em outro estudo, Hellström (2007) realizou pesquisa qualitativa com entrevistas de profundidade para compreender como indivíduos superaram ambivalências e ameaças para se engajarem em trabalho coletivo, reafirmando o grupo (estruturação) e enriquecendo a própria individualidade. O engajamento dos participantes no projeto colaborativo não cerceava a individualidade, claramente exposta e argumentada nas inovações propostas ao projeto, sendo os acordos coletivos temporários e provisórios. As decisões não eram tomadas por votação, mas por consensos diante das soluções encontradas pelo esforço coletivo. Esses são estudos voltados para situações concretas e restritas, mas que dão uma dimensão prática e factível ao trato com a complexidade. $\mathrm{Na}$ verdade, já há esforços institucionais para lidar com essas polaridades por meio de integração interdisciplinar, como, por exemplo, o Centro para o Estudo dos Processos de Grupo, promovido pelo Departamento de Sociologia da Universidade de lowa, EUA, e o Centro para o Estudo do Indivíduo e da Sociedade, promovido pelo Departamento de Psicologia da Universidade de Minnesota, EUA.

\section{Conclusões}

Talvez correndo o risco de se carregar um pouco nas cores, podemos afirmar que o conjunto de dilemas e de tensões que marcam o campo da Psicologia e das práticas psicológicas o configura como um território minado, ou, quem sabe, um terreno acidentado, recortado, dividido, com grupos atentos para a defesa do seu território e o ataque a territórios estranhos. As nossas conhecidas orientações teóricometodológicas podem ser vistas como pacotes fechados ou quase fechados de formas de se equacionar esse amplo conjunto de dilemas mencionado no início desta exposição. Esse mosaico tensionado é trabalhado por muitos como próprio da natureza da Psicologia, e esta deve ser vista como um campo plural, diverso. Qualquer tentativa de se perseguir uma identidade está condenada ao fracasso.

Quais as implicações dessas tensões e polaridades no campo da formação? Tais grupos em disputa pelo poder - científico e de formação de novas gerações - ocupam/ desocupam espaços curriculares. A dinâmica de poder no interior dos coletivos responsáveis pela estruturação dos currículos faz com que o aluno tenha ou não acesso a uma ou outra abordagem, quando não se segregam áreas fundamentais, por discordâncias epistemológicas ou por reserva de espaço político.

Como todos nós sabemos, o núcleo central que definiu a identidade da nossa profissão tem, historicamente, como elementos básicos, o trabalho clínico, de base individual. Apesar de todas as transformações ocorridas ao longo dos últimos trinta anos e da crítica contundente feita aos limites sociais de tal prática, os sinais de mudança nesse núcleo de identidade são ainda muito tímidos. Mesmo inseridos em organizações, sejam de educação, de saúde, de serviço ou de indústria, parte importante das nossas práticas ainda tem como unidade as pessoas, e não as coletividades. Mesmo aquelas práticas que se dizem coletivas, talvez a um exame mais minucioso revelem que não se está atuando, efetivamente, no nível das redes que interligam as pessoas e que as tornam interdependentes. Que ferramentas teóricas e metodológicas já possuímos para ampliar as modalidades de intervenção? Simplesmente ab-rogar intervenções individuais por considerá-las 
elitistas ou envolver-se em ações coletivas sem articular redes e recursos não nos parece um caminho promissor.

As polaridades que demarcam o nosso campo de pesquisa e profissão requerem maiores estudos. Apesar de problema tão central para a compreensão de qualquer fenômeno psicológico, psicossocial, psicossociológico ou sociológico, maior clareza de como lidar com a polaridade indivíduo-coletividade possui implicações nítidas para quaisquer práticas, tanto no nível dos indivíduos como no dos grupos, das organizações e da sociedade. $\mathrm{O}$ inadequado tratamento dessas tensões pode levar a entendimentos e explicações que nos aprisionem no reducionismo de ambos os lados, especialmente quando tratamos o coletivo como coisa, com existência independente das ações humanas que as concretizam. Isso é muito claro, por exemplo, no caso das organizações e mesmo quando se utiliza o conceito de cultura. Estamos aqui diante do reducionismo ao qual se referiu
Elias (1994), de transformar processos em estados, isto é, no primeiro passo para que tais estados sejam tomados como coisas, como substantivos e, portanto, passem a integrar o nosso discurso explicativo dos fenômenos psicológicos e psicossociais.

Em síntese, polaridades e dilemas são características marcantes e identificadoras dos muitos segmentos e frações do nosso campo. Sendo assim, não podemos temêlas e nem escondê-las, sob a forma de uma conciliação fácil entre opostos. Ampliar os nossos esforços para aprender a lidar com as armadilhas da nossa linguagem, como nos advertiu Francis Bacon séculos atrás (Hearnshaw, 1987), é o desafio maior posto a professores e pesquisadores. Só assim nossos alunos deixarão de repetir posicionamentos a partir de simpatias ou antipatias pessoais e estaremos ajudando-os a serem construtores ativos do seu processo de formação científicoprofissional.

\footnotetext{
Antonio Virgilio B. Bastos

Doutorado em Psicologia pela Universidade de Brasília. Coordenador da Área de Psicologia da CAPES, Universidade Federal da Bahia - BA - Brasil.

E-mail: antoniovirgiliobastos@gmail.com

William Barbosa Gomes

Professor do Instituto de Psicologia da Universidade Federal do Rio Grande do Sul, pesquisador 1A do CNPq, Rio Grande do Sul - RS - Brasil.

E-mail: gomesw@ufrgs.br
}

Endereço para envio de correspondência:

Universidade Federal da Bahia, Centro de Estudos Interdisciplinares para o Setor Público.

Av. Ademar de Barros S/N - Pav. 4, Ondina, Salvador - BA - Brasil. CEP: 40170-110 
Almeida Filho, N. (1997). Transdisciplinaridade e saúde coletiva. Ciência e Saúde Coletiva 2, 5-19.

Archer, M. S. (2003). Structure, agency and internal conversation. Cambridge, UK: Cambridge University Press.

Ayres, J. R. C. M. (2001). Sujeito, intersubjetividade e práticas de saúde. Ciência e Saúde Coletiva, 6(1), 63-72.

Baillargeon, R. (2008). Innate ideas revisited: For a principle of persistence in infants' physical reasoning. Perspectives on Psychological Science, 3(1), 2-13.

Barnard, C. I. (1979). As funções do executivo. São Paulo: Atlas. (Trabalho original publicado em 1938).

Barrett, L. F. (2009). The future of psychology: Connecting mind and brain. Perspective on Psychological Science, $4(4), 326-339$

Bourdieu, P. (1989). O poder simbólico (F. Tomaz, trad.). Rio de Janeiro: Bertrand Brasil (Trabalho original publicado em francês, 1989).

David, O., \& Bar-Tal, D. (2009). A sociopsychological conception of collective identity: The case of national identity as an example. Personality and Social Psychology Review, 13(4), 354-379.

Denzin, N., \& Lincoln, Y. S. (2000). Handbook of qualitative research. Thousands Oaks, CA: Sage Publications.

Durkheim, E. (1972). As regras do método sociológico (M. I. P. Queiroz, trad.). São Paulo: Companhia Editora Nacional (Trabalho original publicado em francês, 1895).

Elias, N. (1994). A sociedade dos indivíduos (V. Ribeiro trad.). Rio de Janeiro: Zahar (Trabalho original publicada em alemão, 1990).

Etzioni, A. (1989). Organizações modernas. São Paulo: Pioneira. (Trabalho original publicado 1964).

Ganellen, R. J. (2007). Assessing normal and abnormal personality functioning: Strengths and weakness of self-report, observer, performance-based methods. Journal of Personality Assessment, 89(1), 30-40.

Giddens, A. (2003). A constituição da sociedade (A. Cabral, trad.) São Paulo: Editora Martins Fontes.

Hall, R. H. (1984). Organizações: estrutura e processos. Rio de Janeiro: Prentice-Hall do Brasil Ltda.

Harré, R., \& Lamb, R. (1991). Diccionario de psicologia social y de la personalidad (J. Piatigorsky, Trad.). Buenos Aires: Paidos (Trabalho original publicado em inglês, 1981).
Hearnshaw, L. S. (1989). The shaping of modern psychology. London: Routledge.

Hellström, T. (2007). The individual vs. the group? Individualization and collectivity among students in collaborative design. International Journal of Technology and Design Education, 17, 305-321.

Juckes, T., \& Barresi, J. (1993). The subjective-objective dimension in the individual-society connection: A duality perspective. Journal for the Theory of Social Behavior, 23(2), 197-216.

Keating, D. P. (Ed.). (2007). Nature and nurture in early child development. Cambridge, UK: Cambridge University Press.

Kimble, G. A. (1984). Psychology's two cultures. American Psychologist, 39(8), 833-839.

Lewkowicz, D. J. (2011). The biological implausibility of the nature - nurture dichotomy and what it means for the study of infancy. Infancy, 16(4), 331-367.

Morin, E. (1996). O problema epistemológico da complexidade. Lisboa: Publicações Europa-América.

Nunez, N., Poole, D. A., \& Menon, A. (2003). Psychology's two cultures revisited: Implications for the integration of science with practice. The Scientific Review of Mental Health Practice, 2, 8-9.

Searle, J. R. (1995). The construction of social reality. New York: Free Press.

Simon, H. (1979). Comportamento administrativo. Rio de Janeiro: Editora da Fundação Getúlio Vargas. (Trabalho original publicado em 1945).

Staw, B. M., \& Sutton, R. I. (1993). Macro organizational psychology. In J. K. Murninghan (Ed.), Social psychology in organizations - Advances in theory and research (pp. 350-384). Englewood Cliffs, NJ: Prentice-Hall, Inc.

Strauss, A. L. (1999). Espelhos e máscaras: a busca de identidade (G. G. Souza, trad.). São Paulo: Editora da USP.

Weber, M. (1994). Economia e sociedade: fundamentos da sociologia compreensiva (R. Barbosa \& K. Barbosa, trads.). Brasília, DF: Editora Universidade de Brasília (Trabalho original publicado em alemão, 1922).

Wiley, N. (1994). The semiotic self. Chicago: The University of Chicago Press. 